\title{
A 368-year maximum temperature reconstruction based on tree-ring data in the northwestern Sichuan Plateau (NWSP), China
}

\author{
Liangjun $\mathrm{Zhu}^{1}$, Yuandong Zhang ${ }^{2}$, Zongshan $\mathrm{Li}^{3}$, Binde $\mathrm{Guo}^{1}$, and Xiaochun Wang ${ }^{1}$ \\ ${ }^{1}$ Center for Ecological Research, Northeast Forestry University, Harbin 150040, China \\ ${ }^{2}$ Key Laboratory of Forest Ecology and Environment, State Forestry Administration, Institute of Forest Ecology, \\ Environment and Protection, Chinese Academy of Forestry, Beijing 100091, China \\ ${ }^{3}$ State Key Laboratory of Urban and Regional Ecology, Research Center for Eco-Environmental Science, \\ Chinese Academy of Sciences, Beijing 100085, China
}

Correspondence to: Xiaochun Wang (wangxc-cf@nefu.edu.cn) and Yuandong Zhang (zydxju@ 163.com)

Received: 10 January 2016 - Published in Clim. Past Discuss.: 3 February 2016

Revised: 15 April 2016 - Accepted: 16 June 2016 - Published: 13 July 2016

\begin{abstract}
We present a reconstruction of July-August mean maximum temperature variability based on a chronology of tree-ring widths over the period AD 1646-2013 in the northern part of the northwestern Sichuan Plateau (NWSP), China. A regression model explains $37.1 \%$ of the variance of July-August mean maximum temperature during the calibration period from 1954 to 2012. Compared with nearby temperature reconstructions and gridded land surface temperature data, our temperature reconstruction had high spatial representativeness. Seven major cold periods were identified $(1708-1711,1765-1769,1818-1821,1824$ 1828, 1832-1836, 1839-1842, and 1869-1877), and three major warm periods occurred in 1655-1668, 1719-1730, and 1858-1859 from this reconstruction. The typical Little Ice Age climate can also be well represented in our reconstruction and clearly ended with climatic amelioration at the late of the 19th century. The 17th and 19th centuries were cold with more extreme cold years, while the 18th and 20th centuries were warm with less extreme cold years. Moreover, the 20th century rapid warming was not obvious in the NWSP mean maximum temperature reconstruction, which implied that mean maximum temperature might play an important and different role in global change as unique temperature indicators. Multi-taper method (MTM) spectral analysis revealed significant periodicities of 170-, 49-114-, 25-32-, 5.7-, 4.6-4.7-, 3.0-3.1-, 2.5-, and 2.1-2.3-year quasi-cycles at a $95 \%$ confidence level in our reconstruction. Overall, the
\end{abstract}

mean maximum temperature variability in the NWSP may be associated with global land-sea atmospheric circulation (e.g., ENSO, PDO, or AMO) as well as solar and volcanic forcing.

\section{Introduction}

The northwestern Sichuan Plateau (NWSP), located between the body of Tibetan Plateau and the Sichuan Basin, is the transition zone of the Tibetan Plateau and the second step of China, which is one of the most sensitive and vulnerable areas to climate change (IPCC, 2013). Frequent temperaturerelated natural disasters, especially in summer (e.g., hailstones, frost damage), have a major influence on the natural ecosystem and human activities over the entire NWSP areas (Zheng and Yao, 2006; Ma, 2006). The climate in the NWSP is complexly influenced by large-scale atmospheric circulation patterns, such as Asian monsoon and El NiñoSouthern Oscillation (ENSO), Atlantic Multidecadal Oscillation (AMO), and Pacific Decadal Oscillation (PDO) (Shao and Fan, 1999; Song et al., 2007; Duan et al., 2010; Yu et al., 2012; Xiao et al., 2013, 2015; Deng et al., 2014), but driving mechanisms are not fully known or understood.

Long temperature records in the NWSP are particularly critical for us to understand variability in past temperature variations and influences of large-scale atmospheric circulations as well as possible forcing mechanisms in order to pre- 
dict future climate (Liang et al., 2008; Thapa et al., 2015). Therefore, it is essential to explore long-term temperature variability from model-validated climate proxy data. However, most instrumental meteorological records in the NWSP are of short length, covering only the past 40-60 years, and thus provide little information on climate variability over decades and longer.

Natural proxies, such as ice cores, speleothems, pollens, lake sediments, and tree rings, have the potential to fulfill this task (IPCC, 2013). Tree-ring data, a major proxy for paleoclimate research, have been widely used to reconstruct past climate worldwide (Bräuning and Mantwill, 2004; Gou et al., 2008; Deng et al., 2014; Thapa et al., 2015; Wang et al., 2015) due to accurate dating, wide distribution, high resolution, and good replication (Stokes and Smiley, 1968; Fritts, 1976). In recent years, rapid progress in dendroclimatic reconstructions has occurred throughout China (Zhang, 2015). Among these reconstructions, only a few occurred in the NWSP. Unfortunately, most of them were reconstructed temperature in a single month in summer or continuous months in winter and measured mean or minimum temperature rather than mean maximum temperature (Shao and Fan, 1999; Song et al., 2007; Duan et al., 2010; Yu et al., 2012; Xiao et al., 2013, 2015; Deng et al., 2014).

Global warming has already been regarded as an indisputable fact (IPCC, 2013). Recent studies suggest that global warming has occurred mainly in minimum temperatures and at night in most regions of Northern Hemisphere; however, evidence of warming trends of maximum temperatures was not apparent; variations in the mean, minimum, and maximum temperatures were asymmetric during the warming processes. It is suggested that we should focus more attention on reconstructing various temperature variables (e.g., maximum and minimum temperatures) but not mean temperature (Wilson and Luckman, 2002; Wilson and Luckman, 2003). Therefore, the aims of the present study are to (1) develop new tree-ring-width chronologies for the timberline forests in the NWSP, (2) reconstruct past mean maximum temperature variations in late summer using the tree-ring chronology, (3) analyze and compare this reconstruction with the existing reconstruction and historical data archives in the NWSP, and (4) identify possible driving mechanisms of late summer temperature in this area.

\section{Materials and methods}

\subsection{Study area}

Samples were collected from spruce (Picea purpurea) growing at timberline of the mountain Ayila in the township of Chali, located in the NWSP $\left(32^{\circ} 43^{\prime} 49^{\prime \prime} \mathrm{N}, 102^{\circ} 06^{\prime} 17^{\prime \prime} \mathrm{E}\right.$; $3900 \mathrm{~m}$ above sea level, a.s.l.). This region is classified as a sub-humid climate and is strongly influenced by Asian monsoon, with dry periods from November to April and wet periods from May to October (Fig. 1). Based on records from
Table 1. Information of two weather stations sites nearest to sampling sites.

\begin{tabular}{lll}
\hline Weather stations & Hongyuan & Aba \\
\hline Long $(\mathrm{E})$ & $102^{\circ} 33^{\prime}$ & $101^{\circ} 41^{\prime}$ \\
Lat $(\mathrm{N})$ & $32^{\circ} 48^{\prime}$ & $32^{\circ} 54^{\prime}$ \\
Elev. $(\mathrm{m})$ & 3248 & 3254 \\
$P(\mathrm{~mm})$ & 749.89 & 740.77 \\
$T\left({ }^{\circ} \mathrm{C}\right)$ & 1.53 & 3.43 \\
$T_{\max }\left({ }^{\circ} \mathrm{C}\right)$ & 10.24 & 12.22 \\
$T_{\min }\left({ }^{\circ} \mathrm{C}\right)$ & -5.35 & -2.93 \\
Period & $1960-2013$ & $1955-1990$ \\
DWS $(\mathrm{km})$ & 42.4 & 42.3 \\
\hline
\end{tabular}

Note: $P$ is annual total precipitation; $T, T_{\max }$, and $T_{\min }$ are annual mean, maximum, and minimum temperature, respectively; and DWS is the distance from the weather station to the sampling site of Chali.

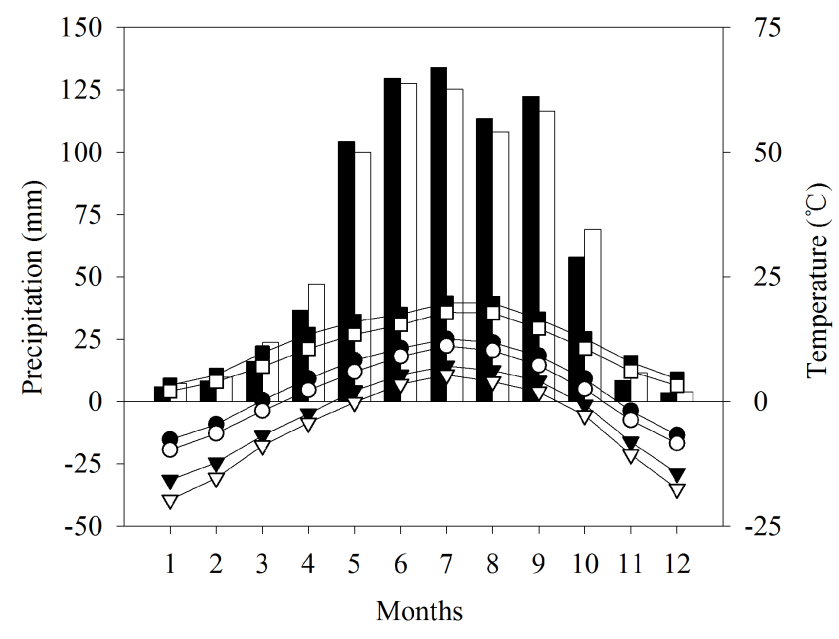

Figure 1. Monthly variation in total precipitations (bars), mean maximum temperature (lines with squares), mean temperature (lines with circles), and mean minimum temperature (lines with triangles) in Hongyuan (white) and Aba (black) meteorological stations, calculated for the period of 1961-2013 and 1955-1990, respectively.

the two nearest weather stations in Aba (1955-1990) and Hongyuan (1962-2013), the mean annual temperatures are 3.4 and $1.5^{\circ} \mathrm{C}$, the mean monthly minimum temperatures are -5.4 and $-2.9^{\circ} \mathrm{C}$, and the mean monthly maximum temperatures are 10.2 and $12.2^{\circ} \mathrm{C}$ (Table 1). The regional average annual precipitation ranges from 500 to $1000 \mathrm{~mm}$, is highly variable on interannual timescales, and falls predominantly during the summer monsoon season (May to October, 86$89 \%$; Fig. 1).

The dark coniferous forests in this area are distributed within narrow bands on both sides of valley and generally reach an altitude of $3500-4000 \mathrm{~m}$ a.s.l. $P$. purpurea is the most widespread and dominant species with $80 \%$ coverage, mainly growing on typical mountain brown dark coniferous 


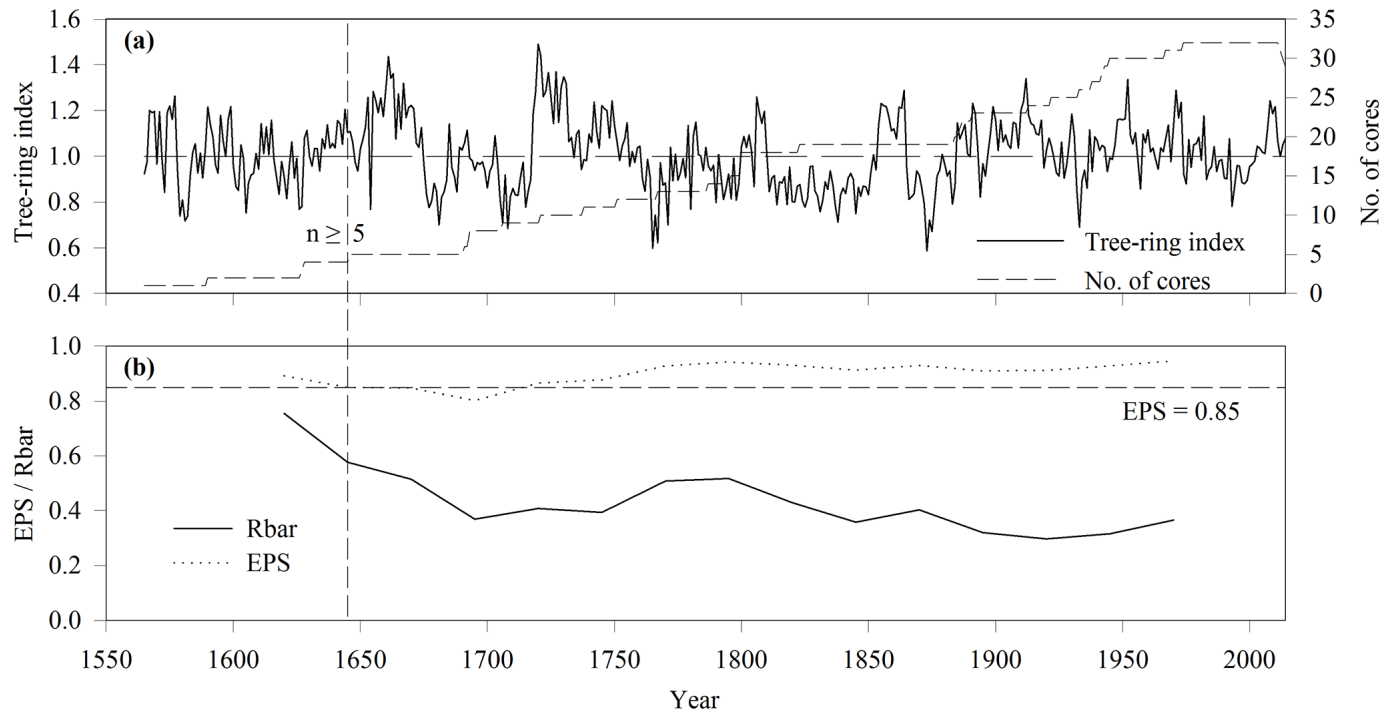

Figure 2. The tree-ring chronology of Picea purpurea at timberline in Chali. (a) Standard chronology and sample size changing with time. (b) Rbar and EPS (see text for explanation) plotted for 50-year windows with 25-year overlap for the standard chronology. The vertical dashed line represents the cut-off point when the $n \geq 5$ and EPS $>0.8$. The horizontal dashed line represents the theoretical 0.85 threshold.

forest soils (according to the Chinese Soil Taxonomic System) (Yang et al., 1992; Li, 1995). As a shallow-root tree species, $P$. purpurea is able to endure shade and humid conditions in addition to extreme cold, so that it usually grows at high altitudes where only a thin soil layer is covering the bedrock. The vegetation of this area is sub-alpine dark coniferous forests dominated by spruce, fir, and cypress forests as well as some pines, birch, and oaks, at low altitudes (Yang et al., 1992).

\subsection{Tree-ring data}

In July 2014, a total of 36 increment cores from 16 live trees were collected on opposite sides using an $5 \mathrm{~mm}$ diameter increment at breast height ( $1.3 \mathrm{~m}$ above ground level) to avoid or reduce errors in different sides caused by topography, competition, climate, and growth characteristics. In order to remove the influence of identifiable stand disturbances (including animal and human disturbance, windstorm, snow, and fire damage) and any obvious abnormal growth, each sample tree and sampling area was selected carefully. According to traditional dendrochronological procedures (Fritts, 1976; Cook and Kairiukstis, 1990), all cores were fixed by trough and air-dried at room temperature for 2-3 days in laboratory. Afterwards, we progressively sanded those cores to a fine polish until individual tracheids within annual rings were visible. Then, cross-dating was performed to assign calendar years to each growth ring and identify possible false or absent rings using a skeleton-plot crossdating method (Stokes and Smiley, 1968), and subsequently tree-ring width was measured at $0.001 \mathrm{~mm}$ resolution using a semiautomatic Velmex tree-ring measurement system
(Velmex, Inc., Bloomfield, NY, USA). Cross-dating and measurement accuracy were checked first visually and then statistically using the COFECHA computer program (Holmes, 1983). To remove the non-climate signals related to tree age or the effects of stand dynamics, cross-dated ring widths were detrended and standardized by fitting a conservative negative exponential curve or linear curve with negative slope using the ARSTAN program (Cook, 1985). We calculated ring-width indices for each specimen by dividing the ring-width value by the value of the fitted curve for each year. The resulting ring-width indices were averaged together to generate a standard chronology for collection site (Cook, 1985) (Fig. 2).

The quality of composite tree-ring chronology was evaluated by estimating the mean correlation between series (RBAR) and expressed population signal (EPS). The RBAR provides an indication of chronology signal strength (common variance between all series) and is independent of sample size, whereas the EPS assesses the degree to which the chronology represents a hypothetical chronology based on an infinite number of cores and is calculated from betweentree correlation and number of trees included in the calculation (Wigley et al., 1984). Running RBAR and EPS statistics were calculated for 51-year intervals of the chronology with 25-year overlaps to assess the stability of signal strength as chronology replication diminished back in time. EPS has an overall mean of 0.90 , well above the generally accepted 0.85 cut-off (Wigley et al., 1984) except for a brief period in the 1690s when it falls to just above 0.8 (the Rbar decline to 0.37). The lower EPS and Rbar values ca. 1695 (Fig. 2) seem to result from suppressed growth during this cool period in more mature trees and somewhat erratic juve- 
nile growth in the trees entering the chronology about this time. Although the EPS remains $>0.85$ early in the record (ca. 1620), which might be caused by the inflated Rbar due to a higher percentage of correlations being computed from within the same trees. To extend the length of the chronology, we thus consider this chronology to be most reliable over the past 368 years (AD 1646-2013), which corresponds to a minimum sample depth of five cores (four trees) for our chronology (Fig. 2).

\subsection{Climate and statistical analyses}

Instrumental climatic data in this study, provided by the China Meteorological Data Sharing Service System (http: //data.cma.cn/), were available from the weather stations of Hongyuan $\left(32^{\circ} 48^{\prime} \mathrm{N}, 102^{\circ} 33^{\prime} \mathrm{E} ; 3248 \mathrm{~m}\right.$ a.s.l.) and $\mathrm{Aba}$ $\left(32^{\circ} 54^{\prime} \mathrm{N}, 1101^{\circ} 41^{\prime} \mathrm{E} ; 3254 \mathrm{~m}\right.$ a.s.l.). These were the two nearest stations to the tree-ring sampling sites of Chali, with a maximum distance of about $42 \mathrm{~km}$ (Table 1). With similar seasonal rainfall distribution and climatic conditions, the Hongyuan and Aba meteorological stations cover the period 1961-2013 and 1955-1990 of instrumental data, respectively (Fig. 1). Large-scale climate data (Atlantic Multidecadal Oscillation, AMO; Pacific Decadal Oscillation, PDO; multivariate ENSO index, MEI) were downloaded from the KNMI climate explorer (http://climexp.knmi.nl/).

In order to determine the relationship between tree growth and climate factors, the initial observed climatic data (total precipitations, mean, minimum, and maximum temperatures) from the previous July to current September of the two stations were used to perform a correlation analysis. Based on a stronger relationship between tree-ring index and previous July to August mean maximum temperature of Hongyuan and Aba, we reconstructed regional late summer (from July to August) mean maximum temperature (hereafter RLST) using a simple linear regression model. In order to obtain a long calibration/verification period of JulyAugust mean maximum temperatures, the July and August mean maximum temperature in the two stations were extended to the period 1955-2013 using linear regression of records from Hongyuan and Aba stations before reconstruction. Models explain $87 \%$ of the variance in mean maximum temperature of July (correlation 0.93 ) and $92 \%$ of the variance of August (correlation 0.96), which indicates that variations in temperature with time during the overlapping period have been very similar throughout the region.

A traditional split-period calibration/verification method was used to explore the temporal stability and reliability of the reconstruction model (Fritts, 1976; Cook and Kairiukstis, 1990). Multiple statistical parameters, including Pearson's correlation coefficient $(r), R$ square $\left(R^{2}\right)$, the sign test (ST), the reduction of error (RE), the coefficient of efficiency (CE), the product means test (PMT), the Durbin-Watson (DW) test, and the root mean square error (RMSE), were used to evaluate model ability of this method (Fritts, 1976; Cook and Kair- iukstis, 1990). To examine the temporal and spatial representativeness of the temperature reconstruction, spatial correlation between actual and reconstructed RLST variables in this study as well as gridded $\left(0.5^{\circ} \times 0.5^{\circ}\right)$ temperature data from 1955 to 2012 (CRU TS3.22 maximum temperature; Harris et al., 2014) was performed using the KNMI climate explorer (http://climexp.knmi.nl/). We also compared our RLST reconstruction for the past 368 years with other tree-ring-based temperature reconstructions from nearby areas and over a large scale. We further filtered those reconstructions with 11and 61-year moving average and discussed the similarities among them in terms of decadal to multidecadal variations. Moving correlations were used to visualize and describe the periods of agreement and disagreement.

A spectral analysis was performed to identify the periodicity of local climate variability reconstructed in this study using a multi-taper method (MTM) program (Mann and Lees, 1996). Teleconnections between reconstructed RLST variables and monthly optimum interpolation sea surface temperature $\left(0.5^{\circ} \times 0.5^{\circ}\right.$, monthly OISST $)$ were also performed to verify the potential driving of large-scale climate on local temperatures. The NOAA monthly OISST is an analysis constructed by combining observations from different platforms (satellites, ships, buoys) on a regular global grid. Although the monthly OISST data are short (1982-now), they are more accurate; thus, we chose them instead of other SST data.

Superposed epoch analysis (SEA) was used to test the presence of a volcanic cooling signal in our reconstruction (Haurwitz and Brier, 1981). In this case, an 11-year window was used, 6 years before and 4 years after the event years. Departures from the mean temperature values for the key years and for windows of years were superposed and averaged to determine whether temperature for these years was significantly different from randomly selected sets of 11 other years (Fischer et al., 2007). A standard $t$ test and a Monte Carlo method were used to test the significance of the means, and 10000 simulations were performed by random resampling to determine the probability associated with the average departures for the volcano key dates (Haurwitz and Brier, 1981). SEA was conducted using software FHAES version 2.0.0 (https://www.frames.gov/partner-sites/ fhaes/download-fhaes/). According to Davi et al. (2015), a large tropical volcanic event year list $(1601,1642,1763$, 1810, 1816, 1836, 1992) generated from Gao et al. (2008) was used to estimate of global volcanic forcing during the years 1554-2012. These years were chosen based on querying the global forcing series for years with negative forcing of at least the magnitude of the 1991 Pinatubo eruption, and then using only the first year if there were multiple consecutive years with large negative forcing. 

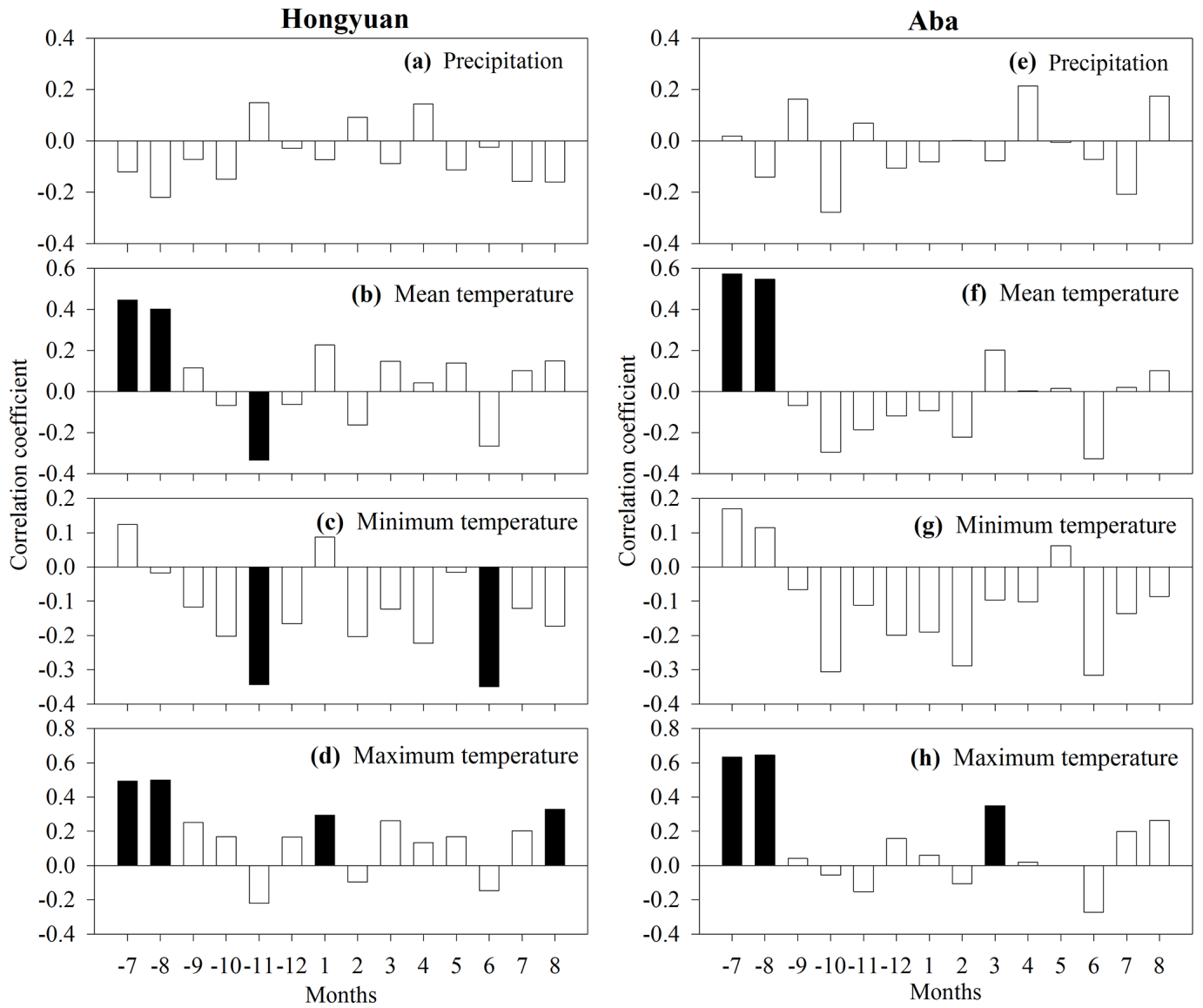

Figure 3. Correlation analyses between the Chali tree-ring chronology and meteorological climate data of Hongyuan and Aba including total precipitation (a, e), mean temperature $(\mathbf{b}, \mathbf{f})$, minimum temperature $(\mathbf{c}, \mathbf{g})$, and maximum temperature $(\mathbf{d}, \mathbf{h})$. The black-filled bars represent significant effects at $95 \%$ significant levels.

\section{Results}

\subsection{Tree growth-climate relationships}

We used simple correlation analysis to identify climate signals in ring-width chronology through SPSS software (IBM, Armonk, New York). Relationships between Chali chronology and Hongyuan and Aba monthly climate data are shown in Fig. 3. A significant positive correlation $(p<0.05)$ between tree radial growth of $P$. purpurea and mean and maximum temperature in the previous July and August was found at both of the weather stations, which indicated that the late summer mean maximum temperature in the previous year played a vital role for radial growth of $P$. purpurea. Ringwidth chronology of $P$. purpurea was negatively $(p<0.05)$ associated with previous November mean and minimum temperature at the Hongyuan weather station, and a similar negative correlation relationship was also found at the Aba weather station, though not at a significant level. There was a significant negative correlation $(p<0.05)$ between tree radial growth of $P$. purpurea and mean minimum temperature in June found at the Hongyuan weather station; however, it was not significant at the Aba weather stations. The correlations between monthly precipitation data and the ring-width index were not significant at both weather stations. Therefore, we selected July-August mean maximum temperature as the target of our reconstruction.

\subsection{Regional temperature reconstruction}

We reconstructed RLST history based on the strong relationship between previous July and August mean maximum temperature and tree-ring index (TRI). A simple linear regression model between TRI and the composite July-August mean maximum temperature of Hongyuan and Aba weather stations covering from 1955 to 2013 was created to reconstruct the regional temperature history. The model is as follows:

$$
\begin{gathered}
T_{\mathrm{JAt}}=5.35 I_{t+1}+13.36,\left(r=0.61, N=58, R^{2}=37.1 \%,\right. \\
\left.R_{\mathrm{adj}}^{2}=36.9 \%, F=32.97, P<0.001\right),
\end{gathered}
$$

where $T_{\mathrm{JAt}}$ is RLST at year $t$ and $I_{t+1}$ is the ring-width index at year $t+1$. The RLST reconstruction model accounted for $37.1 \%$ (36.9\% after adjusting for the degrees of freedom) of 

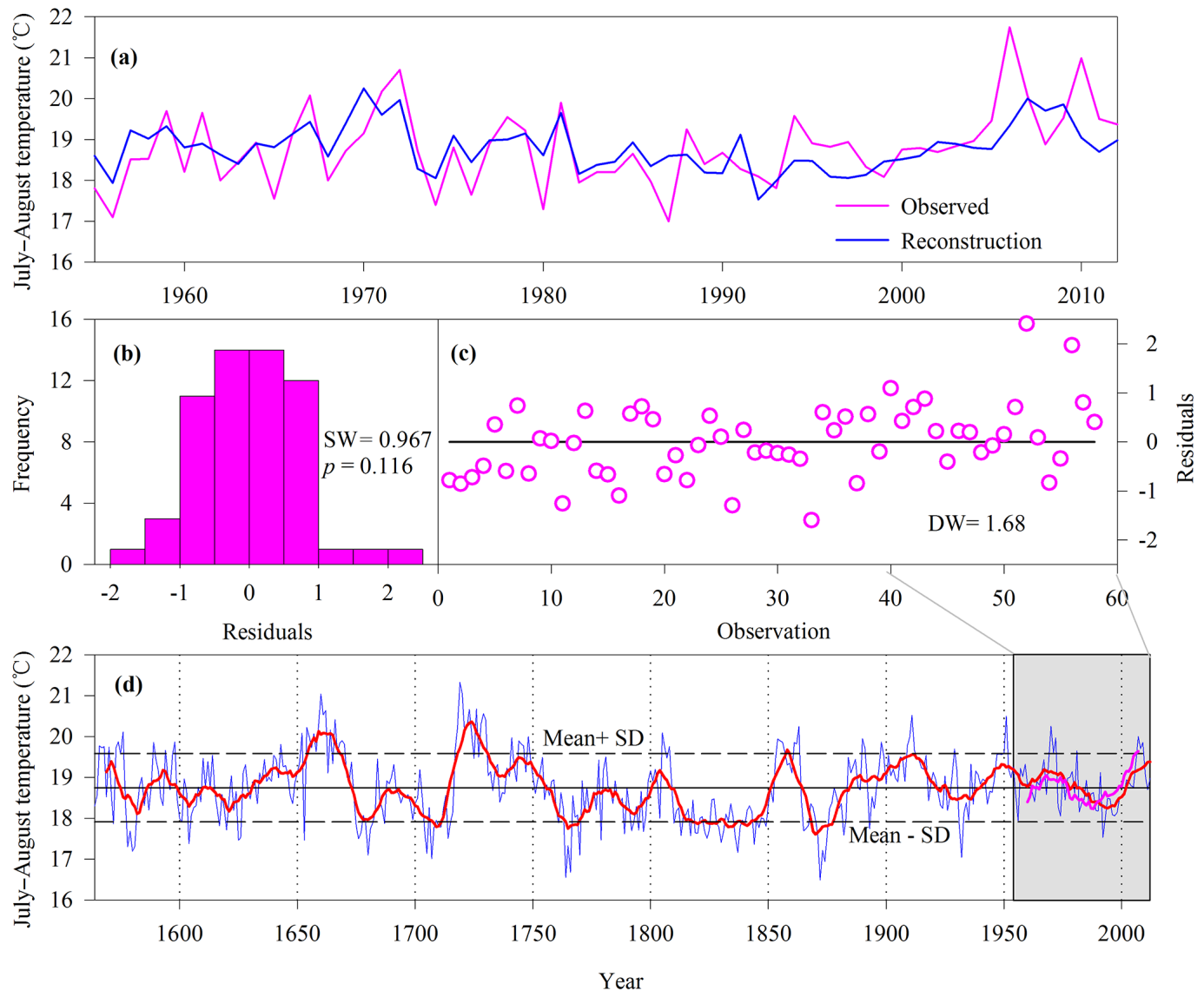

Figure 4. Temperature reconstruction in the NWSP, China. (a) The comparison of observed (pink line) and reconstructed (blue line) regional July-August mean maximum temperature during the calibration period 1955-2012. (b) Shapiro-Wilk residuals normality test (SW). (c) Durbin-Watson test for residuals autocorrelation (DW). (d) Annual and 11-year smoothed regional July-August mean maximum temperature reconstruction (blue and red lines, respectively); superimposed is the 11-year smoothed instrumental record (pink line).

Table 2. Calibration and verification statistics for the regional July-August mean maximum temperature reconstruction.

\begin{tabular}{lllllllllll}
\hline Calibration & $r$ & $R^{2}$ & Verification & $R^{2}$ & RE & CE & ST & PMT & DW & RMSE \\
\hline $1955-2012$ & $0.61^{* *}$ & $0.37^{* *}$ & - & - & 0.37 & - & $(41,17)^{* *}$ & $6.46^{* *}$ & 1.68 & 0.73 \\
$1955-1984$ & $0.78^{* *}$ & $0.61^{* *}$ & $1985-2012$ & $0.28^{* *}$ & 0.26 & 0.21 & $(21,8)^{*}$ & $4.04^{* *}$ & 1.99 & 0.82 \\
$1985-2012$ & $0.53^{* *}$ & $0.28^{* *}$ & $1955-1984$ & $0.61^{* *}$ & 0.61 & 0.59 & $(24,5)^{* *}$ & $4.63^{* *}$ & 1.69 & 0.62 \\
\hline
\end{tabular}

${ }^{*}=p<0.05 .{ }^{* *}=p<0.01$

the composite mean maximum temperature variance for calibration period from 1955 to 2012 (Fig. 4a, Table 2). Shown in Fig. 4a, our temperature reconstruction could not fully capture the magnitude of extraordinary warm or cold years at high frequency, especially in the last few years, similar to other tree-ring reconstructions (Deng et al., 2014; Thapa et al., 2015), but it paralleled the general tendency of composite RLST during calibration period. Spatial correlation analysis showed a similar general pattern between the observed and estimated RLST compared with gridded temperature records (Fig. 5). These results suggest that our reconstructions pro- vide some information about late summer mean maximum temperature variability in the NWSP.

Split-period calibration/verification analysis (Fritts, 1976; Cook and Kairiukstis, 1990) was used to test the stability and reliability of the regression model including statistical parameters of $r, R^{2}, \mathrm{RE}, \mathrm{CE}, \mathrm{ST}, \mathrm{PMT}$, DW, and RMSE. Two rigorous tests of fit, the RE and $\mathrm{CE}$, were both strongly positive (Table 2), indicating that the model was significantly and considerably skillful in reconstructing observed variations (Fritts, 1976; Cook and Kairiukstis, 1990). The statistical parameters of $R^{2}$, ST, and PMT all exceeded the 95 or 

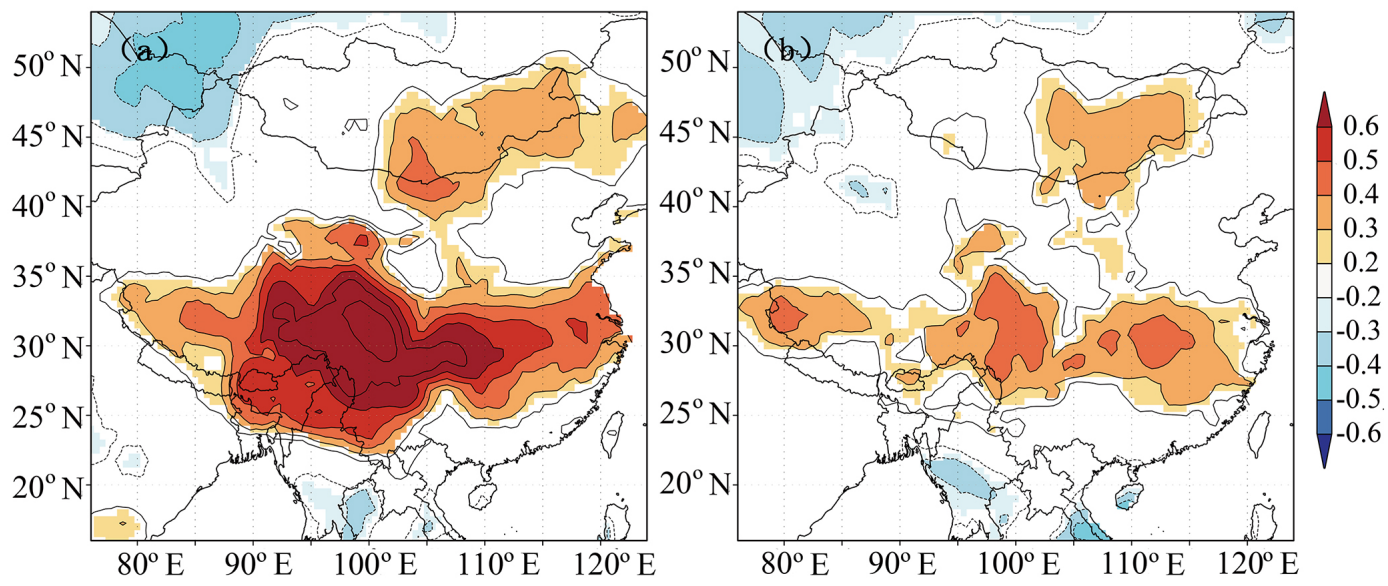

Figure 5. Spatial correlation fields of (a) instrumental and (b) reconstructed July-August mean maximum temperature for the NWSP with regional gridded July-August mean maximum temperature for the period 1955-2011.

$99 \%$ confidence level. Moreover, the RMSE value was relatively small in our model. The DW, used to analyze reconstruction residuals from a regression analysis, ranged from 1.68 to 1.99 , indicating no significant autocorrelation or linear trends among our residuals (Fig. 4b-c; Table 2). Upon successful validation of the two split-period models, regression parameters for the full calibration period were used to reconstruct RLST back to AD 1645 based on the ring-width record.

\subsection{Regional temperature variations}

According to the regression equation, our reconstructed RLST could be extended back to AD 1645 with a mean of $18.75^{\circ} \mathrm{C}$ and a standard deviation (SD) of $\pm 0.84^{\circ} \mathrm{C}$ (Fig. 4b). In this paper, we defined those having values (11-year moving average series) exceeding $19.59^{\circ} \mathrm{C}$ $($ mean $+\mathrm{SD})$ as extremely warm periods, while those not exceeding $17.91{ }^{\circ} \mathrm{C}$ (mean $+\mathrm{SD}$ ) were defined as extremely cold periods. The Little Ice Age (LIA) climate can be well represented and clearly ended with climatic amelioration at the end of the 19th century (Fig. 7b). In the nearly 400-year timescale, the 17th and 19th centuries were cold with more extreme cold years, while the 18th and 20th centuries were warm with less extreme cold years. The 20th century rapid warming was not obvious in the NWSP mean maximum temperature reconstruction (Fig. 7b). Moreover, relatively cold periods occurred during 1708-1711, 1765-1769, 18181821, 1824-1828, 1832-1836, 1839-1842, and 1869-1877. Warm periods prevailed during 1655-1668, 1719-1730, and 1858-1859. Among them, the 10 coldest yeas were identified as 1872 (16.49), 1764 (16.55), 1766 (16.68), 1874 (16.94), 1707 (17.01), 1932 (17.05), 1680 (17.1), 1770 (17.1), 1705 (17.15) and 1837 (17.16), and the top 10 warmest years were 1719 (21.33), 1720 (21.05), 1660 (21.04), 1726 (20.68),
1723 (20.66), 1662 (20.64), 1729 (20.56), 1661 (20.53),1911 (20.52), and 1951 (20.5).

During the period 1875-1955, late summer temperature fluctuated less strongly than before or thereafter. In general, the average length of cold periods was shorter than that of warm periods. The cold period of 1869-1877 was the longest and coldest cool period had a mean of $17.63^{\circ} \mathrm{C}$. The longest warm period extended from 1655 to 1668 , and the warmest period in AD 1719-1730 had a mean of $20.37^{\circ} \mathrm{C}$. However, we should point out that the rapid warming during the 20th century was not especially obvious in our reconstructed RLST.

A multi-taper method (MTM) of spectral analysis (Mann and Lees, 1996) was performed to identify major periodicities present in the full range of our reconstruction. The result of spectral analysis over the full range (1645-2012) showed that there were significant periodicities at 2-2.3, 2.5, 3-3.1, $4.6-4.7,5.6,25-32$, and 53-93 years at the $95 \%$ confidence level (Fig. 6).

\section{Discussion}

\subsection{Climate-growth relationship}

Temperature, especially winter or growing season temperature, limits tree growth at alpine and subalpine treelines at high latitudes of the Northern Hemisphere, as suggested by previous dendroclimatic and seasonal cambial activity studies (Körner and Paulsen, 2004; Rossi et al., 2008; Seo et al., 2013). Large temperature sensitivity, especially during the summer season, has also been clearly demonstrated in tree line sites of the eastern Tibetan Plateau (Fan et al., 2009; Zhu et al., 2011; Li et al., 2012). In our study, the radial growth of $P$. purpurea was significantly positive correlated to mean and maximum temperature in July and August of the previous year, which suggests that previous late summer 


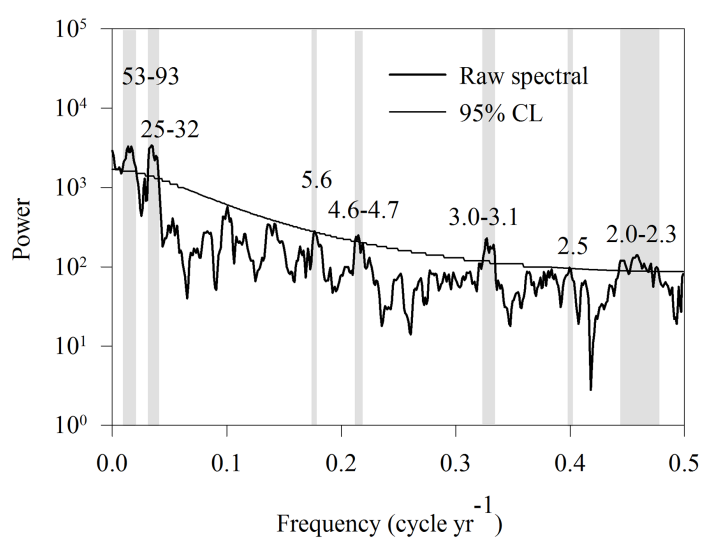

Figure 6. Multi-taper method power spectrum of the reconstructed July-August temperature for the period AD 1645-2012. The $95 \%$ confidence level relative to red noise is shown by the dashed curve. The gray area indicates the $95 \%$ significance level and the numbers refer to the significant period in years.

temperature was the major limiting factor to tree-ring growth of $P$. purpurea in the NWSP, China (Fig. 3). Similar results showed that the radial growth of $P$. purpurea was greatly limited by late summer temperature of previous and current years (Bräuning and Mantwill, 2004; Ren et al., 2014), which has been reported by previous studies in nearby areas. Most of these have been used to reconstruct the historical temperature variations (Bräuning and Mantwill, 2004; Ren et al., 2014). Tree-ring chronologies were an indicator of late summer temperature, which was also found at high-elevation conifer sites on the eastern Tibetan Plateau (Bhattacharyya and Chaudhary, 2003; Bräuning and Mantwill, 2004), which further suggested that the spruce growth at the timberline in this area was greatly affected by previous late summer temperature.

The lagged relationship to climate is common in dendroclimatology analyses (Bräuning and Mantwill, 2004; Gou et al., 2006; Duan et al., 2010; Zhu et al., 2011; Li et al., 2012), which usually involved the use of stored photosynthetic products during the current growing season and/or developmental processes (e.g., leaf maturation, root elongation) in the previous growing season (Fritts, 1976). It is possible that more non-structural carbohydrates (NSCs) and other organic substances, which could be used to produce more wood in the next spring at high-elevation sites, were synthesized in a warmer late summer (Li et al., 2008). In contrast, by increasing the frequency of frost and missing rings and limiting the growth of roots and their function in water uptake (Körner and Paulsen, 2004), a narrow ring would usually be formed and fewer NSCs and other organic substances would be synthesized in a cold late summer.

Tree growth at timberlines depended not only on growing season temperature but also occasionally on winter temperatures, which could cause frost drought in evergreen conifers (Oberhuber, 2004; Elliott, 2012). Generally, the radial growth of $P$. purpurea had a negative relationship with winter (from previous October to current April, especially in November) mean and minimum temperature rather than maximum temperature (Fig. 3). Warm winters were often accompanied by low snow cover, which might particularly and likely lead trees to suffer from enhanced frost desiccation as a result of increased transpiration rates of needles and shoots, photoinhibitory stress, and short-term fluctuations in shoot temperatures, leading to xylem embolism (Sperry and Robson, 2001). Sustained winter defoliation at timberline had an overwhelming influence on subsequent radial growth (Payette et al., 1996; Oberhuber, 2004). However, more snow protects plants against these stresses during the cold season (Sakai and Larcher, 1987). Those temperature-induced stresses effect could explain the negative correlation between the tree growth and winter temperature. Therefore, significant positive correlations of the radial growth of $P$. purpurea with the previous late summer mean and maximum temperature and positive correlation of the radial growth of $P$. purpurea and the previous winter mean minimum temperature were reasonable and meaningful in this study, based on inferences from known physiological processes.

\subsection{Comparison with regional records}

To assess whether our reconstruction represents features and evaluate the spatial synchrony of temperature variation, a spatial correlation analysis was performed between the $0.5^{\circ} \times 0.5^{\circ}$ gridded July-August mean maximum temperature data (CRU TS3.22; Harris et al., 2014) for the period 1955-2012 over a large region in the NWSP. Both the observed and reconstructed late summer temperature in the NWSP showed a similar spatial correlation pattern with regional temperature records, which was coherent over a large spatial scale, including most of the Tibetan Plateau, central and eastern regions of China, and parts of Mongolia and Inner Mongolia, China (Fig. 6). We also compared our reconstruction with other tree-ring-based temperature reconstructions in surrounding regions (Fig. 7). The RLST variations in the NWSP were coherent over a large spatial scale, also including most of the Tibetan Plateau, central and eastern regions of China, and parts of Mongolia and Inner Mongolia, China. July-August mean temperature, based on treering data obtained nearby our study site, in the north of western Sichuan of Xiao et al. (2015) was significantly positively $(r=0.122, p=0.028)$ associated with our reconstruction (Fig. 7). Additionally, a significant positive correlation $(r=0.1, p=0.039)$ between our reconstruction and February-June temperature reconstruction for Kathmandu (Cook et al., 2003), located farther from our study site, was also found (Fig. 7). Both the sites (farther away from and near to our study site) displayed highly synchronous variation patterns with our reconstruction overall, which further validated results of spatial correlation analysis. Moving cor- 


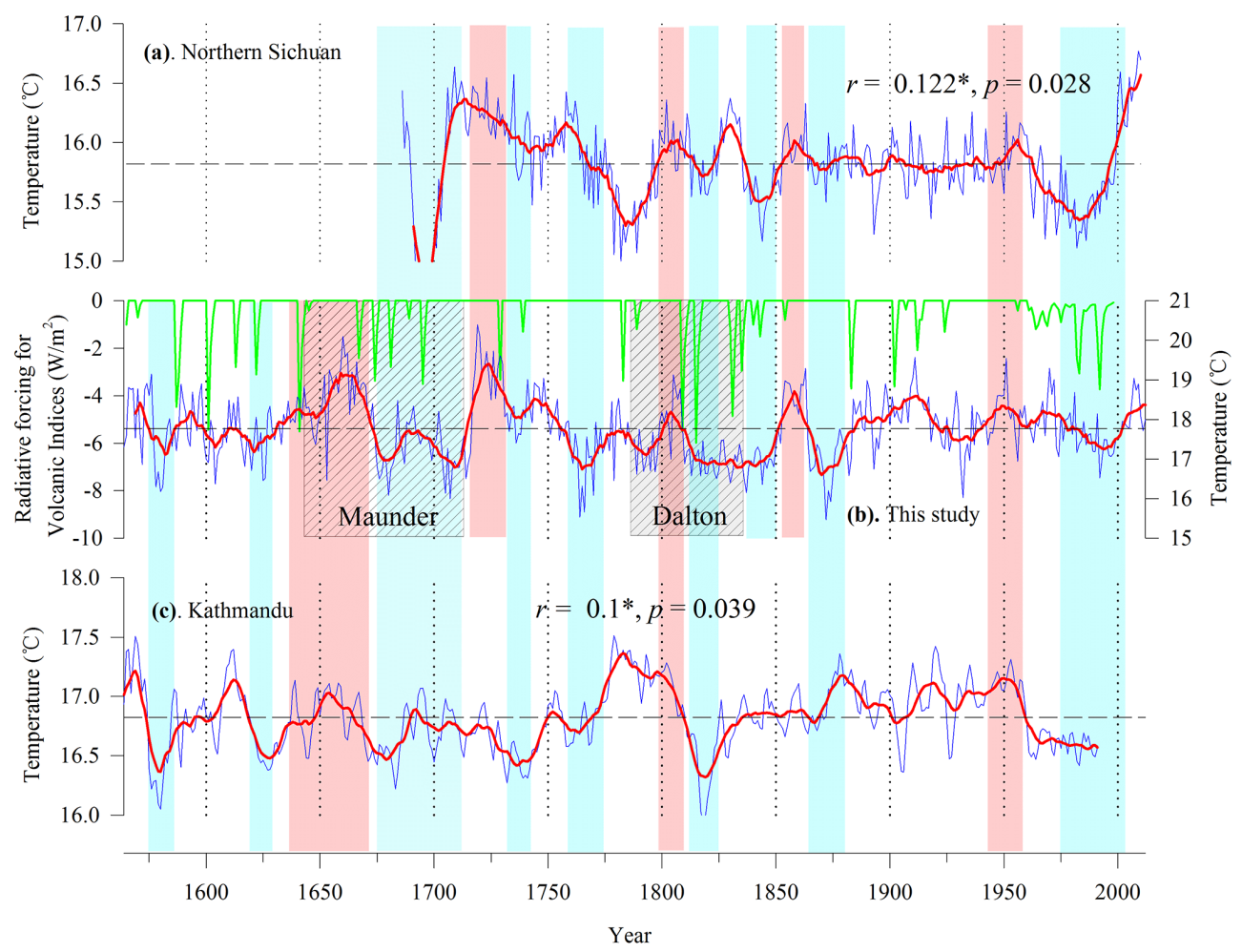

Figure 7. Comparison of July-August mean maximum temperature reconstruction of the NWSP in this study with other tree-ring-based temperature reconstructions. (a) July-August mean temperature in northwestern Sichuan (Xiao et al., 2015). (b) July-August mean maximum temperature reconstruction in the NWSP (this study); the cyan curve is radiative forcing for ice core volcanic indices series after adjustments (Crowley, 2000) and the two hatched boxes show the Maunder and Dalton solar minima periods. (c) February-June temperature reconstruction in Kathmandu (Cook et al., 2003). All temperature series (blue curve) are smoothed with an 11-year moving average (red curve). Light-blue (cold) and red (warm) shading represents low- and high-temperature zones with good agreements in these temperature series, respectively.

relation analysis showed that our temperature reconstructions were similar to those of Xiao et al. (2015) (except the period 1876-1975) and Cook et al. (2003) (except the periods 16761825 and 1876-1975) in decadal variations (11-year moving average) and also showed consistency with Xiao et al. (2015) (except the period 1826-1925) and Cook et al. (2003) (except the period 1676-1825) in multidecadal variations (61year moving average) (Fig. 8). The correlation relationships between Xiao et al. (2015) and Cook et al. (2003) with our reconstruction were the opposite pattern, significantly negative and positive or positive and negative correlations between our reconstruction and the reconstructions of Xiao et al. (2015) and Cook et al. (2003) were identified in the years of 1676-1975 (Fig. 8). Such widespread temporal and spatial variability in temperature has been found in previous studies (Legates and Willmott, 1990; Yang, 2001). However, those decadal or multidecadal differences between them might be due to differences in season, species, and the different standardization approach applied on tree-ring data (Thapa et al., 2015). In addition, inherent differences in climate variables and in climate-driven mechanisms were also the main sources of differences. For example, variations in the mean, minimum, and maximum temperatures were often asymmetric (Wilson and Luckman, 2002, 2003; Gou et al., 2008). Asymmetric variability between mean, minimum, and maximum temperatures was also found at the Hongyuan weather stations, especially the differences between mean minimum and maximum temperature.

The LIA climate in our reconstruction can be well reflected and clearly ended with climatic amelioration at the end of the 19th century (Fig. 7b), though the magnitude and timing of maximum glacierization varied regionally, especially in the vast and complex terrain of China (Yang, 2001). In the nearly 400-year timescale, the 17th and 19th centuries were cold with more extreme cold years, while the 18th and 20th centuries were warm with less extreme cold years, which were consistent with Yang (2001). It was noteworthy that 20th century warming (Song et al., 2007; Zhu et al., 2011; IPCC, 2013) was not very obvious in our reconstruction, which was in line with recent studies that global warming has occurred mainly in the minimum temperatures and at night in most regions of the Northern Hemisphere; however, evidence of the warming trend of the maximum temperatures was not clear (Wilson and Luckman, 2002, 2003). More- 


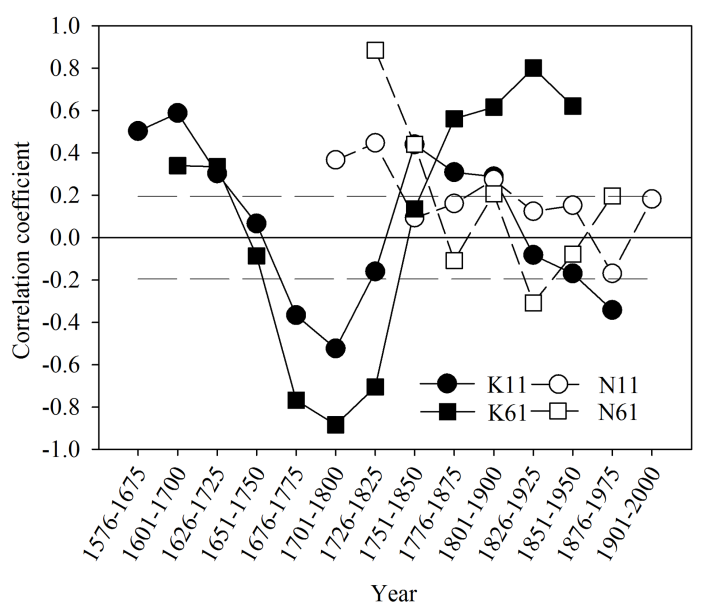

Figure 8. Moving correlation function coefficients calculated between our reconstructed temperatures and other temperature reconstructions in decadal (running 11-year mean) and multidecadal variations (running 61-year mean). N: July-August mean temperature in northwestern Sichuan (Xiao et al., 2015), K: February-June temperature reconstruction in Kathmandu (Cook et al., 2003). Period: 1576-2000; moving window: 100 years; overlap: 25 years.

over, seven cold periods and three warm periods were identified during the past 368 years (Fig. 4d). All the cold periods were during the Maunder (1708-1711) or Dalton (1818$1821,1824-1828,1832-1836$, and 1839-1842) solar minima periods, except for the cold periods of 1765-1769 and 1869-1877 (Eddy, 1976; Shindell et al., 1999), which indicated that RLST variations in the NWSP might be driven by solar activity (Fig. 7b). On the other hand, volcanic eruptions in the corresponding periods might also be a cooling factor (Fig. 7b). A longer cold period (e.g., 1820s-1840s) was interrupted by transient warming, thus forming a plurality of discontinuous short cold periods. Warm periods of 1719-1730 and 1858-1859 both had more sunspots (Eddy, 1976; Shindell et al., 1999) and lower volcanic forcing (Fig. 7b). The cold (1765-1769 or 1869-1877) and warm (1655-1668) periods were highly consistent with other studies (Fig. 7). It is hard to explain the cold (1765-1769 or 1869-1877) or warm (1655-1668) periods without or with obvious volcanic and solar forcing (Fig. 7b), but it might be linked with volcanic and solar activities (Haurwitz and Brier, 1981; Shindell et al., 1999; Fischer et al., 2007; Gao et al., 2008; Anchukaitis et al., 2013; Stoffel et al., 2015). In short, our regional reconstruction could be a good representative of the past late summer maximum temperature variations in the NWSP.

\subsection{Possible forcing mechanism}

Results of MTM analysis revealed that some significant dominant periodicities existed in our reconstructed regional temperature variability (Fig. 6). Among them, significant highfrequency periodicities around 5.7, 4.6-4.7, 3.0-3.1, 2.5, and
Table 3. Correlation of the smoothed (11-year moving average) temperature reconstruction and other large-scale climate system cycles.

\begin{tabular}{llll}
\hline Month & AMO $(n=156)$ & PDO $(n=112)$ & MEI $(n=62)$ \\
\hline PMAY & -0.15 & $-0.43^{* *}$ & $-0.43^{* *}$ \\
PJUN & $-0.19^{*}$ & $-0.26^{* *}$ & $-0.42^{* *}$ \\
PJUL & $-0.19^{*}$ & $-0.27^{* *}$ & $-0.32^{*}$ \\
PAUG & $-0.17^{*}$ & $-0.27^{* *}$ & $-0.27^{*}$ \\
PSEP & $-0.17^{*}$ & $-0.24^{*}$ & $-0.27^{*}$ \\
POCT & -0.07 & $-0.19^{*}$ & $-0.29^{*}$ \\
PNOV & -0.05 & $-0.21^{*}$ & $-0.26^{*}$ \\
PDEC & -0.07 & $-0.21^{*}$ & $-0.28^{*}$ \\
JAN & -0.00 & $-0.34^{* *}$ & $-0.28^{*}$ \\
FEB & -0.13 & $-0.29^{* *}$ & $-0.27^{*}$ \\
MAR & -0.13 & $-0.39^{* *}$ & $-0.38^{* *}$ \\
APR & -0.13 & $-0.39^{* *}$ & $-0.41^{* *}$ \\
MAY & $-0.18^{*}$ & $-0.46^{* *}$ & $-0.43^{* *}$ \\
JUN & $-0.22^{* *}$ & $-0.31^{* *}$ & $-0.42^{* *}$ \\
JUL & $-0.22^{* *}$ & $-0.30^{* *}$ & $-0.31^{*}$ \\
AUG & $-0.21^{* *}$ & $-0.30^{* *}$ & $-0.28^{*}$ \\
\hline
\end{tabular}

AMO: Atlantic Multidecadal Oscillation; PDO: Pacific Decadal Oscillation; MEI: multivariate ENSO index. ${ }^{*} p<0.05 .{ }^{* *} p<0.01$.

2.1-2.3 years, falling within the range of an ENSO cycle of 2-8 years (Philander, 1989), were found in our reconstruction, which indicated that ENSO might affect the late summer temperature variability in the NWSP. Consistent with this observation, ENSO may have a strong influence on temperature variability in neighboring dendroclimatological research, such as northwestern Yunnan (Fan et al., 2009; Li et al., 2012), the Tibetan Plateau (Bhattacharyya and Chaudhary, 2003; Bräuning and Mantwill, 2004; Gou et al., 2006, 2008; Zhu et al., 2011), and the western Sichuan Plateau (Duan et al., 2010). Strong teleconnections of ENSO with interannual variability in tree growth and local temperature with tropical ocean-atmosphere systems have been found in nearby sites (Liang et al., 2008; Deng et al., 2014). Based on these results we performed correlation analysis of the smoothed (11-year moving average) temperature series with extended multivariate ENSO index (MEI; Wolter and Timlin, 2011). A significant negative correlation was found between estimated RLST and MEI from the previous May to current August (Table 3), revealing that the cool (warm) previous and current SSTs might have a significant impact on late summer temperature in the NWSP. Similar results were detected in western Nepal Himalaya region (Thapa et al., 2015) and northern China (Lu, 2005). These high-frequency cycles around 2-3 years might also be linked to the quasibiennial oscillation (QBO; Labitzke and Van Loon, 1999) and tropospheric biennial oscillation (TBO; Meehl, 1987), which may also suggest strong teleconnections of local temperature variability with tropical ocean-atmosphere systems. The significant cycle around 25-32 years might be linked to Pacific Decadal Oscillation (PDO; Mantua et al., 1997), and 
significantly negative correlations of our smoothed (11-year moving average) temperature reconstruction with PDO index from the previous May to current August were also detected (Table 3). PDO signals had been found in tree rings in large-scale Asian regions (D'Arrigo and Wilson, 2006). Accompanied by significant peaks at 60.2 and 73 years, the continuously periodicities around 49-114 years in our regional temperature reconstruction might tentatively be related to PDO, Atlantic Multidecadal Oscillation (AMO; Enfield et al., 2001) as well as solar activity (Eddy, 1976; Shindell et al., 1999; Peristykh and Damon, 2003; Raspopov et al., 2004; Braun et al., 2005). The AMO was an important driver of multidecadal variations in summer climate not only in North America and western Europe (Kerr, 2000; Sutton and Hodson, 2005) but also in the East Asia (Feng and Hu, 2008; Liang et al., 2008; Wang et al., 2011, 2015; Zhu et al., 2011). The 60.2-year peak associated with AMO demonstrated that multidecadal variations in late summer temperature in the NWSP might be controlled by AMO. This was also consistent with recent findings; the AMO could change the land-sea thermal contrast between the East Asian continents, thus affecting temperature of the East Asian (Feng and Hu, 2008; Wang et al., 2011). Further, correlation analysis between the smoothed (11-year moving average) temperature reconstruction and the monthly AMO index was calculated to test this hypothesis. A significant negative correlation during the previous July to September period and current May to August period was detected (Table 3), which further confirmed the powerful influence of AMO on late summer temperatures in northwestern Sichuan. In addition, we also found significant cycles at more than 147 years with peaks at 170 years. Considering the limited length of our reconstruction (368 years), this cycle might not be reliable and must be interpreted with caution, although there have been similar findings using temperature reconstruction in the eastern Tibetan Plateau (Deng et al., 2014; Wang et al., 2015). Strong teleconnections between reconstructed RLST variables and monthly July-August OISSTs of the Pacific, Indian, and Atlantic oceans were also found (Fig. 9). The RLST variables significantly correlated with the SSTs changes, especially the west and equatorial Pacific as well as the North Atlantic oceans (Fig. 9), which further verified the driving of large scale climate (e.g., ENSO, PDO, and AMO) on the RLST in the NWSP from another angle.

In addition to large-scale climate, solar and volcanic forcing might be also the key factors in driving the RLST variability in the NWSP. Regional temperatures associated with solar activity in northwestern Sichuan have been found (Shao and Fan, 1999; Xiao et al., 2013, 2015); even the classic 11year sunspot cycle (Shindell et al., 1999) was not significant in our temperature reconstruction. However, those significant multidecadal- and centennial-scale cycles of our temperature reconstruction might include the signs of solar activity, such as the Gleissberg cycles (Peristykh and Damon, 2003), Suess cycles (Braun et al., 2005), Bruckner cycles (Raspopov et al.,

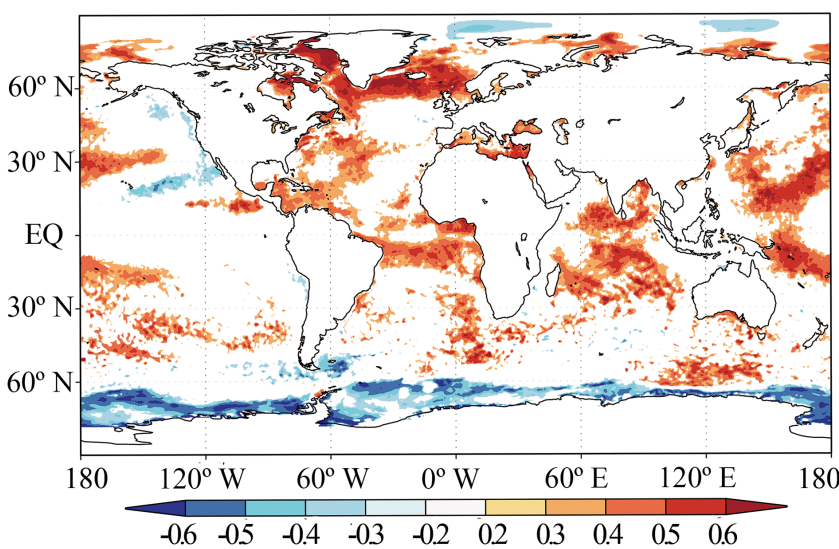

Figure 9. Spatial correlations between estimated temperatures and monthly OISSTs at the global scale. The spatial correlations were carried out for the months July-August covering a time span from 1982 to 2012.
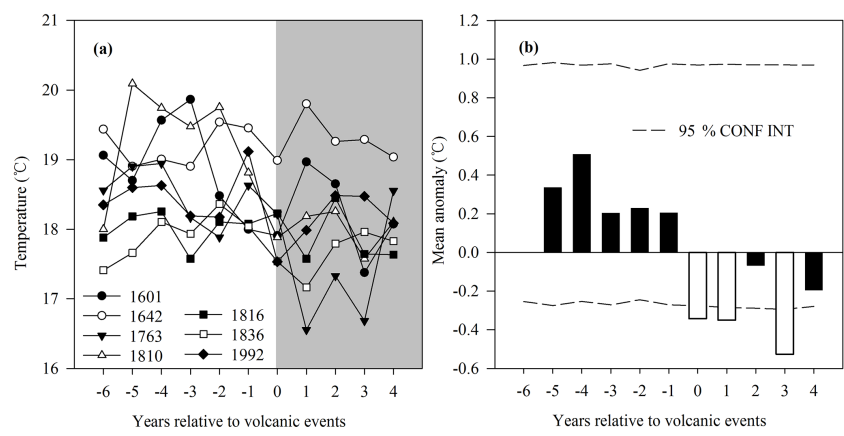

Figure 10. The influence of volcanic forcing on temperature variations. Temperature change around the volcanic eruptions (a) and results of the superposed epoch analysis (SEA) for volcanic cooling (b).

2004), and Schwabe cycles (Braun et al., 2005). The Maunder (ca. AD 1645-1715) and Dalton (ca. AD 1790-1840) solar minima periods were generally associated with temperature depressions (Eddy, 1976), and the Damon (ca. AD 18901920) solar maximum period occurred in a relatively warm period, which further confirmed that late summer temperature variation in the NWSP might be driven by solar activity (Fig. 7b). In addition, volcanic cooling can influence tree growth, such as the formation of frost rings, light rings, and missing rings, and provides accurate, impartial, and coherent information on the timing and magnitude of such events and their influence on the climate system (Fischer et al., 2007; Gao et al., 2008; Anchukaitis et al., 2013; Stoffel et al., 2015). Cooling associated with explosive volcanic eruptions can also be found in our reconstruction of temperatures (Fig. 7b). The radiative forcing for ice core volcanic indices series after adjustments (Crowley, 2000) and our temperature reconstructions present high consistency (Fig. 7b). Most volcanic eruption events lead to a temperature drop in the year of 
the event and subsequent years, especially in 1763 and 1810 (Fig. 10a). The result of SEA also shows significant cooling occurred during the year of the event (in year 0 ) as well as the following years (in year 1,3) (Fig. 10b). Other dendroclimatological studies in the Tibetan Plateau, central Asia, Europe, and the Northern Hemisphere also indicated an association between summer temperature reconstructions and volcanic eruptions (Fischer et al., 2007; Liang et al., 2008; Anchukaitis et al., 2013; Davi et al., 2015; Stoffel et al., 2015).

\section{Conclusion}

In this study, a high-resolution tree-ring chronology was used to reconstruct RLST in the NWSP from 1645 to 2012. The model of our reconstruction explains $37.1 \%$ of the temperature variance. Spatial correlations with gridded land mean maximum temperature data and comparison with other nearby temperature reconstructions further revealed that the RLST has a high spatial representativeness, although there have been some temporal or spatial differences at low/highfrequency variability. Seven major cold periods and three major warm periods were identified from this reconstruction, which might be linked with volcanic and solar activities. The Little Ice Age (LIA) climate can also be well represented and clearly end with climatic amelioration at the end of the 19th century. The 18th and 20th centuries were warm with less extreme cold years, while the 17th and 19th century were cold with more extreme cold years. Moreover, the 20th century rapid warming was not obvious in our RLST reconstruction, which implies that mean maximum temperature, as a unique temperature indicator, might play an important and different role in global change. Overall, the RLST variability in the NWSP might be associated with global land-sea atmospheric circulation (e.g., ENSO, PDO, or AMO) as well as solar and volcanic forcing.

\section{Data availability}

The RLST reconstruction in the NWSP will be uploaded to NOAA, and all the data published in this study will be available for non-commercial scientific purposes.

\section{The Supplement related to this article is available online at doi:10.5194/cp-12-1485-2016-supplement.}

Acknowledgements. This research was supported by the National Natural Science Foundation of China (nos. 31370463 and 41471168), the Program for New Century Excellent Talents in University (NCET-12-0810), and the Program for Changjiang Scholars and Innovative Research Team in University (IRT-15R09). We would like to thank Alison Beamish at the University of British Columbia for her assistance with English language and grammatical editing of the manuscript. We also thank the staff of Aba Forestry Bureaus for their assistance in the field.

Edited by: E. Zorita

Reviewed by: two anonymous referees

\section{References}

Anchukaitis, K. J., Breitenmoser, P., Briffa, K. R., Buchwal, A., Büntgen, U., Cook, E. R., D’Arrigo, R. D., Esper, J., Evans, M. N., Frank, D., Grudd, H., Gunnarson, B. E., Hughes, M. K., Kirdyanov, A. V., Körner, C., Krusic, P. J., Luckman, B., Melvin, T. M., Salzer, M. W., Shashkin, A. V., Timmreck, C., Vaganov, E. A., and Wilson, R. J. S.: Tree rings and volcanic cooling, Nat. Geosci., 5, 836-837, doi:10.1038/ngeo1645, 2013.

Bhattacharyya, A. and Chaudhary, V.: Late-summer temperature reconstruction of the Eastern Himalayan region based on tree-ring data of Abies densa, Arct. Antarct. Alp. Res., 35, 196-202, 2003.

Braun, H., Christl, M., Rahmstorf, S., Ganopolski, A., Mangini, A., Kubatzki, C., Roth, K., and Kromer, B.: Possible solar origin of the 1,470-year glacial climate cycle demonstrated in a coupled model, Nature, 438, 208-211, doi:10.1038/nature04121, 2005.

Bräuning, A. and Mantwill, B.: Summer temperature and summer monsoon history on the Tibetan plateau during the last 400 years recorded by tree rings, Geophys. Res. Lett., 31, L24205, doi:10.1029/2004GL020793, 2004.

Cook, E. R.: A time series analysis approach to tree ring standardization, PhD thesis, School of Renewable Natural Resources, University of Arizona, USA, 1985.

Cook, E. R. and Kairiukstis, L. A.: Methods of dendrochronology: applications in the environmental sciences, Kluwer Academic Publishers, Dordrecht, 394 pp., 1990.

Cook, E. R., Krusic, P. J., and Jones, P. D.: Dendroclimatic signals in long tree-ring chronologies from the Himalayas of Nepal, Int. J. Climatol., 23, 707-732, doi:10.1002/joc.911, 2003.

Crowley, T. J.: Causes of climate change over the past 1000 years, Science, 289, 270-277, 2000.

D'Arrigo, R. and Wilson, R.: On the Asian expression of the PDO, Int. J. Climatol., 26, 1607-1617, doi:10.1002/joc.1326, 2006.

Davi, N. K., D’Arrigo, R., Jacoby, G., Cook, E., Anchukaitis, K., Nachin, B., Rao, M., and Leland, C.: A long-term context (9312005 C.E.) for rapid warming over Central Asia, Quaternary Sci. Rev., 121, 89-97, doi:10.1016/j.quascirev.2015.05.020, 2015.

Deng, Y., Gou, X., Gao, L., Yang, T., and Yang, M.: Earlysummer temperature variations over the past $563 \mathrm{yr}$ inferred from tree rings in the Shaluli Mountains, southeastern Tibet Plateau, Quaternary Res., 81, 513-519, doi:10.1016/j.yqres.2013.08.002, 2014.

Duan, J., Wang, L., Li, L., and Chen, K.: Temperature variability since AD 1837 inferred from tree-ring maximum density of Abies fabri on Gongga Mountain, China, Chinese Sci. Bull., 55, 30153022, doi:10.1007/s11434-010-3182-8, 2010.

Eddy, J. A.: The maunder minimum, Science, 192, 1189-1202, doi:10.1126/science.192.4245.1189, 1976.

Elliott, G. P.: Extrinsic regime shifts drive abrupt changes in regeneration dynamics at upper treeline in the Rocky Mountains, USA, Ecology, 93, 1614-1625, 2012.

Enfield, D. B., Mestas-Nuñez, A. M., and Trimble, P. J.: The Atlantic multidecadal oscillation and its relation to rainfall and river 
flows in the continental US, Geophys. Res. Lett., 28, 2077-2080, 2001.

Fan, Z., Bräuning, A., Yang, B., and Cao, K.: Tree ring densitybased summer temperature reconstruction for the central Hengduan Mountains in southern China, Global Planet. Change, 65, 1-11, doi:10.1016/j.gloplacha.2008.10.001, 2009.

Feng, S. and Hu, Q.: How the North Atlantic Multidecadal Oscillation may have influenced the Indian summer monsoon during the past two millennia, Geophys. Res. Lett., 35, 548-562, doi:10.1029/2007GL032484, 2008.

Fischer, E., Luterbacher, J., Zorita, E., Tett, S., Casty, C., and Wanner, H.: European climate response to tropical volcanic eruptions over the last half millennium, Geophys. Res. Lett., 34, 306-316, doi:10.1029/2006GL027992, 2007.

Fritts, H. C.: Tree rings and climate, Academic Press Inc. (London) Ltd., London, UK, 1976.

Gao, C., Robock, A., and Ammann, C.: Volcanic forcing of climate over the past 1500 years: An improved ice core-based index for climate models, J. Geophys. Res.-Atmos., 113, 2036-2044, doi:10.1029/2008JD010239, 2008.

Gou, X., Yang, M., Peng, J., Zhang, Y., Chen, T., and Hou, Z.: Maximum temperature reconstruction for Animaqing Mountains over past 830 years based on tree ring records, Quaternary Sci., 26, 991-998, 2006.

Gou, X., Chen, F., Yang, M., Gordon, J., Fang, K., Tian, Q., and Zhang, Y.: Asymmetric variability between maximum and minimum temperatures in Northeastern Tibetan Plateau: evidence from tree rings, Sci. China Ser. D, 51, 41-55, doi:10.1007/s11430-007-0154-1, 2008.

Harris, I., Jones, P., Osborn, T., and Lister, D.: CRU TS3. 22: Climatic Research Unit (CRU) Time-Series (TS) Version 3.22 of high resolution gridded data of month-by-month variation in climate (Jan. 1901-Dec. 2013), NCAS British Atmospheric Data Centre, 24 September 2014, doi:10.5285/18BE23F8-D252482D-8AF9-5D6A2D40990C, 2014.

Haurwitz, M. W. and Brier, G. W.: A critique of the superposed epoch analysis method: its application to solar-weather relations, Mon. Weather Rev., 109, 2074-2079, 1981.

Holmes, R. L.: Computer-assisted quality control in tree-ring dating and measurement, Tree-Ring Res., 43, 69-78, 1983.

IPCC: Climate change 2013: the physical science basis. Contribution of working group I to the fifth assessment report of the intergovernmental panel on climate change, Cambridge University Press, Cambridge, United Kingdom and New York, NY, USA, 2013.

Kerr, R. A.: A North Atlantic climate pacemaker for the centuries, Science, 288, 1984-1985, doi:10.1126/science.288.5473.1984, 2000

Körner, C. and Paulsen, J.: A world-wide study of high altitude treeline temperatures, J. Biogeogr., 31, 713-732, doi:10.1111/j.1365-2699.2003.01043.x, 2004.

Labitzke, K. G. and Loon, H. V.: The Quasi-Biennial Oscillation (QBO), Springer, Berlin, Heidelberg, 103-112, 1999.

Legates, D. R. and Willmott, C. J.: Mean seasonal and spatial variability in global surface air temperature, Theor. Appl. Climatol., 41, 11-21, doi:10.1007/BF00866198, 1990.

Li, M., Xiao, W., Shi, P., Wang, S., Zhong, Y., Liu, X., Wang, X., Cai, X., and Shi, Z.: Nitrogen and carbon source-sink relationships in trees at the Himalayan treelines compared with lower elevations, Plant Cell Environ., 31, 1377-1387, doi:10.1111/j.1365-3040.2008.01848.x, 2008.

Li, Q.: Sichuan soil, Sichuan Publishing House of Science \& Technology, Chendu, China, 1995.

Li, Z., Zhang, Q., and Ma, K.: Tree-ring reconstruction of summer temperature for AD 1475-2003 in the central Hengduan Mountains, Northwestern Yunnan, China, Climatic Change, 110, 455467, doi:10.1007/s10584-011-0111-z, 2012.

Liang, E., Shao, X., and Qin, N.: Tree-ring based summer temperature reconstruction for the source region of the Yangtze River on the Tibetan Plateau, Global Planet. Change, 61, 313-320, doi:10.1016/j.gloplacha.2007.10.008, 2008.

$\mathrm{Lu}, \mathrm{R} .:$ Interannual variation of North China rainfall in rainy season and SSTs in the equatorial eastern Pacific, Chinese Sci. Bull., 50, 2069-2073, doi:10.1007/BF03322803, 2005.

Ma, L.: China Meteorological Disaster Authority (Sichuan Volume), Meteorological Press, Beijing, China, 2006.

Mann, M. E. and Lees, J. M.: Robust estimation of background noise and signal detection in climatic time series, Climatic Change, 33, 409-445, doi:10.1007/BF00142586, 1996.

Mantua, N. J., Hare, S. R., Zhang, Y., Wallace, J. M., and Francis, R. C.: A Pacific interdecadal climate oscillation with impacts on salmon production, B. Am. Meteorol. Soc., 78, 1069-1079, 1997.

Meehl, G. A.: The Annual Cycle and Interannual Variability in the Tropical Pacific and Indian Ocean Regions, Mon. Weather Rev., 115, 27-50, 1987.

Oberhuber, W.: Influence of climate on radial growth of Pinus cembra within the alpine timberline ecotone, Tree Physiol., 24, 291301, doi:10.1093/treephys/24.3.291, 2004.

Payette, S., Delwalde, A., Morneau, C., and Lavole, C.: Patterns of tree stem decline along a snow-drift gradient at treeline: a case study using stem analysis, Can. J. Botany, 74, 1671-1683, doi:10.1139/b96-203, 1996

Peristykh, A. N. and Damon, P. E.: Persistence of the Gleissberg 88year solar cycle over the last $\sim 12,000$ years: Evidence from cosmogenic isotopes, J. Geophys. Res.-Space, 108, SSH 1-1-SSH 1-15, doi:10.1029/2002JA009390, 2003.

Philander, S. G. H.: El Niño, La Niña and the Southern Oscillation, Academic Press, New York, 293 pp., 1989.

Raspopov, O., Dergachev, V., and Kolström, T.: Periodicity of climate conditions and solar variability derived from dendrochronological and other palaeoclimatic data in high latitudes, Paleogeogr. Paleocl., 209, 127-139, doi:10.1016/j.palaeo.2004.02.022, 2004.

Ren, J., Liu, Y., Song, H., Ma, Y., Li, Q., Wang, Y., and Cai, Q.: The historical reconstruction of the maximum temperature over the past 195 years, Linxia region, Gansu Province - Based on the data from Picea purpurea Mast., Quaternary Sci., 34, 12701279, 2014.

Rossi, S., Deslauriers, A., Griçar, J., Seo, J. W., Rathgeber, C. B., Anfodillo, T., Morin, H., Levanic, T., Oven, P., and Jalkanen, R.: Critical temperatures for xylogenesis in conifers of cold climates, Global Ecol. Biogeogr., 17, 696-707, doi:10.1111/j.14668238.2008.00417.x, 2008.

Sakai, A. and Larcher, W.: Frost survival of plants. Responses and adaptation to freezing stress, Springer-Verlag, New York, 1987.

Seo, J.-W., Eckstein, D., Olbrich, A., Jalkanen, R., Salminen, H., Schmitt, U., and Fromm, J.: Climate control of wood forma- 
tion: illustrated for Scots pine at its northern distribution limit, in: Cellular Aspects of Wood Formation, edited by: Fromm, J., Springer, Berlin, 159-185, 2013.

Shao, X. and Fan, J.: Past climate on west Sichuan Plateau as reconstructed from ring-widths of dragon spruce, Quaternary Sci., 1, 81-89, 1999.

Shindell, D., Rind, D., Balachandran, N., Lean, J., and Lonergan, P.: Solar cycle variability, ozone, and climate, Science, 284, 305308, doi:10.1126/science.284.5412.305, 1999.

Song, H., Liu, Y., Ni, W., Cai, Q., Sun, J., Ge, W., and Xiao, W.: Winter mean lowest temperature derived from tree-ring width in Jiuzhaigou region, China since 1750 AD, Quaternary Sci., 27, 486-491, 2007.

Sperry, J. S. and Robson, D. J.: Xylem cavitation and freezing in conifers, in: Conifer cold hardiness, edited by: Bigras, F. J. and Colombo, S. J., Springer, Berlin, 121-136, 2001.

Stoffel, M., Khodri, M., Corona, C., Guillet, S., Poulain, V., Bekki, S., Guiot, J., Luckman, B. H., Oppenheimer, C., and Lebas, N.: Estimates of volcanic-induced cooling in the Northern Hemisphere over the past 1,500 years, Nat. Geosci., 8, 784-788, doi:10.1038/ngeo2526, 2015.

Stokes, M. A. and Smiley, T. L.: An introduction to tree-ring dating, University of Arizona Press, Arizona, USA, 1968.

Sutton, R. T. and Hodson, D. L.: Atlantic Ocean forcing of North American and European summer climate, Science, 309, 115118, doi:10.1126/science.1109496, 2005.

Thapa, U. K., Shah, S. K., Gaire, N. P., and Bhuju, D. R.: Spring temperatures in the far-western Nepal Himalaya since AD 1640 reconstructed from Picea smithiana tree-ring widths, Clim. Dynam., 45, 2069-2081, doi:10.1007/s00382-014-2457-1, 2015.

Wang, J., Yang, B., and Ljungqvist, F. C.: A millennial summer temperature reconstruction for the eastern Tibetan Plateau from tree ring width, J. Clim., 28, 5289-5304, doi:10.1175/JCLI-D14-00738.1, 2015.

Wang, X., Brown, P. M., Zhang, Y., and Song, L.: Imprint of the Atlantic multidecadal oscillation on tree-ring widths in Northeastern Asia since 1568, PLoS one, 6, e22740, doi:10.1371/journal.pone.0022740, 2011.

Wigley, T. M., Briffa, K. R., and Jones, P. D.: On the average value of correlated time series, with applications in dendroclimatology and hydrometeorology, J. Appl. Meteorol. Clim., 23, 201-213, 1984.
Wilson, R. J. S. and Luckman, B. H.: Tree-ring reconstruction of maximum and minimum temperatures and the diurnal temperature range in British Columbia, Canada, Dendrochronologia, 20, 257-268, 2002.

Wilson, R. J. S. and Luckman, B. H.: Dendroclimatic reconstruction of maximum summer temperatures from upper treeline sites in Interior British Columbia, Canada, Holocene, 13, 851-861, doi:10.1191/0959683603hl663rp, 2003.

Wolter, K. and Timlin, M. S.: El Niño/Southern Oscillation behaviour since 1871 as diagnosed in an extended multivariate ENSO index (MEI. ext), Int. J. Climatol., 31, 1074-1087, doi:10.1002/joc.2336, 2011.

Xiao, D., Qin, N., Li, J., and Li, Y.: Change of mean maximum temperature in July during 1506-2008 in Seda of west Sichuan Plateau according to reconstructed tree-ring series, J. Desert Res., 33, 1536-1543, 2013.

Xiao, D., Qin, N., and Huang, X.: A 325-year reconstruction of July-August mean temperature in the north of west Sichuan derived from tree-ring, Quaternary Sci., 35, 1134-1144, 2015.

Yang, B.: Preliminary study on the temporal and spatial distribution of climatic variations in a decadal resolution since the Litte Ice Age, Arid Land Geogr., 24, 67-73, 2001.

Yang, Y., Li, C., and Guan, Z.: Sichuan forest, Beijing, China Forestry Publishing House, 1992.

Yu, S., Yuan, Y., Wei, W., Zhang, T., Shang, H., and Chen, F. Reconstructed mean temperature in Mearkang, West Sichuan in July and its detection of climatic period signal, Plateau Meteorol., 31, 193-200, 2012.

Zhang, Z.: Tree-rings, a key ecological indicator of environment and climate change, Ecol. Indic., 51, 107-116, doi:10.1016/j.ecolind.2014.07.042, 2015.

Zheng, D. and Yao, T.: Uplifting of Tibetan Plateau with its environmental effects, Adv. Earth Sci., 21, 451-458, 2006.

Zhu, H., Shao, X., Yin, Z., and Huang, L.: Early summer temperature reconstruction in the eastern Tibetan Plateau since AD 1440 using tree-ring width of Sabina tibetica, Theor. Appl. Climatol., 106, 45-53, doi:10.1007/s00704-011-0419-7, 2011. 